\title{
LO POLÍTICO Y LAS POLÍTICAS DE LA DELINCUENCIA JUVENIL. Una reflexión sobre el caso de jóvenes vinculados al Sistema de Responsabilidad Penal Adolescente. Bogotá-Colombia*
}

\author{
Ana Guadalupe Cienfuegos**
}

\section{Resumen}

El presente artículo ofrece una reflexión en torno a lo político, entendido como dimensión constitutiva de las sociedades humanas, en el fenómeno social de la delincuencia juvenil. La reflexión se enmarca en un estudio realizado por la autora en torno a los sentidos y significados del delito en jóvenes vinculados al Sistema de Responsabilidad Penal Adolescente (SRPA) en Bogotá - Colombia ${ }^{1}$ y el análisis conceptual realizado en el marco de una investigación sobre Justicia Restaurativa y Sistema de Responsabilidad Penal Adolescente ${ }^{2}$. Se analizan los resultados de talleres investigativos $y$ entrevistas en profundidad realizadas con jóvenes vinculados al SRPA identificando lo que se constituye para ellos como "político», los sentidos y significados sobre las dimensiones y los

\footnotetext{
* Artículo recibido el 21 de Mayo de 2015. Aceptado el 29 de Julio de 2015.

** Ana Guadalupe Cienfuegos es Psicóloga-Magister en Política Social. Docente investigadora de la Universidad Santo Tomás. Bogotá-Colombia. Consultora en políticas de Salud Mental. Correo electrónico: anacienfuegos@usantotomas.edu.co - cienfuegosa@hotmail.com

1 Sentidos y significados sobre la droga y el delito en jóvenes vinculados al Sistema de Responsabilidad Penal Adolescente. Aportes a las Políticas de prevención del consumo de SPA y la delincuencia juvenil en Bogotá. Trabajo presentado por la autora como tesis de grado para la Maestría de Política Social. Aprobado y reconocido como meritorio en Noviembre de 2013.

${ }^{2}$ La Justicia Restaurativa en el Sistema de Responsabilidad Penal para Adolescentes y la dimensión ética en los Jóvenes y la Comunidad Proyecto de investigación docente de la autora en el programa de Maestría en psicología jurídica de la Universidad Santo Tomás. 2014 - 2016.
} 
escenarios de sus vidas asociados con lo político y las recomendaciones frente a las políticas de prevención y atención de la delincuencia juvenil.

\section{Palabras clave}

Delincuencia juvenil - Responsabilidad Penal Adolescente Político - Políticas.

\section{Abstract}

The main objective of this article is to offer a reflection around the political issue -took as a constitutive dimension of the human societies - took as analytic item on the study about youth crime. The frame of this paper's opinion is an academic study -developed by this article's author - about senses and meanings of criminal activities on young people tied with the Penal Teen Responsibility System in Bogotá - Colombia. Also, this paper's opinion has been made under the umbrella of a research on Repair Justice and Penal Teen Responsibility Systems.

In these two studies, the author analyze workshops and interviews'outputs, made with young people tied with the Penal Teen Responsibility System during 2013, identifying what political issue mean to these people, senses and meanings that relates to it; and finally, drew up advices to policies on youth crime's prevention.

\section{Keywords}

Juvenile delinquency - Juvenile Justice - Policies - Polity. 


\section{Introducción}

Creo, por tanto, que la dimensión epistemológica de la reivindicación de la subjetividad es un medio que nos acerca a la dimensión política.

Jesús Ibáñez

El presente artículo realiza una reflexión en torno a lo político en el fenómeno de la delincuencia juvenil y las concepciones que tienen los jóvenes frente a las políticas de prevención de este fenómeno. A partir del análisis de los resultados de talleres investigativos y entrevistas en profundidad realizadas con jóvenes en conflicto con la ley que se encontraban bajo alguna medida de responsabilidad penal en Bogotá, Colombia. Esta temática adquiere especial interés en el marco de un estudio cualitativo más amplio realizado por la autora, cuya finalidad fue comprender los sentidos y significados sobre las drogas y el delito en jóvenes vinculados al Sistema de Responsabilidad Penal adolescente en Colombia. Los talleres investigativos propuestos incluyeron elementos lúdicos, que permitieron al participante expresar, no solamente, lo que razona en función de construir una narración, discurso o respuesta a una pregunta, sino también compartir, a través del juego, diferentes símbolos, asociaciones, sentidos y significados acerca del fenómeno de la delincuencia juvenil.

Lo político constituye una categoría de análisis quizá más abstracta que práctica. Ante la pregunta ¿Qué es lo político? muchos jóvenes participantes en el estudio respondieron: lo que hacen los políticos; lo que se constituyó inicialmente como algo lejano a su interés; sin embargo, la indagación a fondo en torno a los sentidos y significados que tienen los jóvenes sobre el delito y la relación de estos con los significados asociados a dimensiones como la ética, la intelectualidad y los escenarios como el institucional o el comunitario mostraron una faceta de 'lo político', que aun cuando ocasionalmente los jóvenes no lo nombren como tal, está referida a partes constitutivas de dicha categoría.

Mouffe (2011) plantea una diferenciación entre la política y lo político, considerando dos aproximaciones para explicar la diferencia. Una primera aproximación parte de la ciencia política y se refiere al campo empírico de la política; esto es, según la autora, por un lado, las prácticas e instituciones a través de las cuales se crea un orden determinado, y, por otro lado, una aproximación propia de la filosofía política, que estaría interesada por la esencia de lo político.

En el marco de esta segunda aproximación, Mouffe (2011) reconoce lo político como "el espacio de poder, conflicto y antagonismo" (p. 16) y considera el antagonismo como constitutivo de las sociedades humanas. En la definición de lo político, Mouffe identifica principalmente dos paradigmas: la racionalidad instrumental y la racionalidad comunicativa. El primer paradigma sitúa lo político como un campo instrumental en el que los individuos son guiados por la maximización de intereses particulares. El 
paradigma de racionalidad comunicativa, por el contrario, lo asemeja a un campo deliberativo que supondría un vínculo entre moralidad y política; desde este paradigma, lo político es aprendido mediante la ética o la moralidad.

El trabajo de Mouffe va a centrarse finalmente en los diálogos y tensiones de estos paradigmas en la construcción de sociedades democráticas; no obstante, para los efectos de esta reflexión, si bien la aproximación no deja del todo por fuera la discusión sobre la construcción de sociedades democráticas, en tanto busca aproximarse a una reflexión sobre las respuestas estatales frente al fenómeno de la delincuencia juvenil en sociedades catalogadas como democráticas, lo que se pretende destacar en los aportes de Mouffe es la ubicación de lo político como parte esencial y constitutiva en las sociedades humanas que va más allá del concepto difundido de Polity y Politic ${ }^{3}$ y coloca como centro de lo político a los sujetos éticos individuales y colectivos inmersos en relaciones de poder, conflictos y antagonismos.

En un sentido similar, Montero (2001), en el marco de una propuesta para reconocer la dimensión política de la psicología como campo de conocimiento, define lo político como lo relativo a la vida organizada colectivamente, la relación con los derechos y deberes, el espacio público y las relaciones de poder y sus dinámicas en ese espacio (p. 4) y lo ético como "reflexión general de carácter social, relacional, de la cual se derivan los mandamientos específicos que cada persona deberá implementar en su conducta cotidiana" (p. 5).

Lo político constituye entonces, no solo aquellas maneras de participación formales, explícitas, orientadas y estables en el tiempo (Touraine, 1984 citado por Reguillo, 2003), sino también grupalidades juveniles efímeras, cambiantes, implícitas en sus formulaciones (Reguillo, 2000) y quizá grupalidades llevadas en la ilegalidad, aunque no sean una ruta deseable. "Lo político adquiere corporeidad en las prácticas cotidianas de los actores, en los intersticios que los poderes no pueden vigilar" (Reguillo, 1996 citado por Reguillo, 2003 p. 113).

La delincuencia juvenil, estrechamente asociada a las categorías de bandas juveniles, pandillas juveniles, entre otras denominaciones, constituye también una forma de grupalidad, que si bien trae consigo transgresiones importantes a la convivencia y seguridad ciudadana que deben evitarse, en el caso de adolescentes vinculados con delitos, va más allá de garantizar la seguridad ciudadana y supone el restablecimiento de los derechos de los y las adolescentes. Este proceso de garantía de derechos, en dialogo con el reconocimiento de la responsabilidad del adolescente, debería pasar por la comprensión de las construcciones de grupalidades en torno al delito, en las cuales se construyen identidades colectivas que dotan de sentido las conductas delictivas en contextos determinados.

\footnotetext{
3 Polity: como referido al ámbito del gobierno de las sociedades y Politics como actividad política de pugna por el poder en la sociedad (Ordoñez-Matamoros, 2013. p. 27).
} 
Considerando estas aproximaciones conceptuales, este trabajo se orientó a analizar desde las narrativas de los jóvenes, cómo las acciones y las prácticas asociadas a las conductas delictivas en los jóvenes -las cuales son sustentadas por ellos en función de valores, sentidos y significados otorgados al poder, la justicia, la libertad, la territorialidad, la identidad, la ética y la lealtad-suponen matices políticos.

\section{Metodología}

El presente artículo está basado en los resultados hallados por la autora en la investigación denominada: Sentidos y significados sobre la droga y el delito en jóvenes vinculados al sistema de responsabilidad penal adolescente. Aportes a las Políticas de prevención del consumo de SPA y la delincuencia juvenil en Bogotá (2013) y el análisis teórico realizado también por ella en el marco de una investigación institucional actualmente en desarrollo denominada: La Justicia Restaurativa en el Sistema de Responsabilidad Penal para Adolescentes y la dimensión ética en los Jóvenes y la Comunidad (2015-2016).

Los relatos analizados y divulgados en este artículo corresponden a fragmentos de la primera investigación citada, en la cual no solo se indagó sobre los significados y sentidos alrededor de lo político, sino también por significados asociados a otras dimensiones como lo familiar, lo emocional, lo intelectual, entre otras.

La investigación fue realizada bajo un enfoque cualitativo y utilizó como técnicas centrales de recolección de datos el taller investigativo y la entrevista en profundidad. Ambas técnicas fueron diseñadas por la autora y sometidas a validación de expertos.

El taller investigativo incluyó elementos lúdicos que permitieron al participante expresar no solamente lo que razona en función de construir una narración, discurso o respuesta a una pregunta, sino también expresar a través del juego los diferentes símbolos, asociaciones, sentidos y significados alrededor del fenómeno; esto permitió obtener información verbal de la fase de socialización del taller, e información escrita.

El taller consistió en suministrar a cada participante una figura del cuerpo humano y unas fichas de diferentes colores y formas que correspondían a las diferentes dimensiones y escenarios de la vida cotidiana (política, ética, familiar, intelectual, estética, emocional, física, educativa, institucional). ${ }^{4}$ Se les pedía que imaginaran que la figura humana correspondía a ellos mismos y que cada una de esas dimensiones y escenarios correspondían a escenarios y dimensiones de sus vidas. Cada participante realizó un juego con la figura humana y las fichas que luego socializó con el grupo expresando los motivos de las relaciones establecidas, posiciones, etc., lo cual permitía identificar los significados otorgados a las diferentes dimensiones, escenarios en relación con el cuerpo, el delito y las drogas.

\footnotetext{
${ }^{4}$ Se realizó una explicación sencilla y corta de cada una de estas dimensiones y escenarios pues el ejercicio también suponía indagar sobre los significados y características de las dimensiones y escenarios mismos en relación con las drogas y el delito.
} 
La entrevista en profundidad fue realizada con una guía semiestructurada. En el uso de esta técnica se emplearon preferencialmente preguntas de respuestas abiertas, muy pocas establecidas previamente y en una gran proporción realizadas en el fluir de las entrevistas de acuerdo a los relatos que el participante iba aportando.

Los participantes en el estudio fueron diecinueve adolescentes bogotanos; trece hombres y seis mujeres de entre 14 y 17 años que habían cometido delitos y se encontraban bajo alguna medida del Sistema de Responsabilidad Penal Adolescente, privativas (9 adolescentes) y no privativas de libertad (10 adolescentes). Todos los participantes pertenecían a niveles socioeconómicos bajos (estratos 1 y 2). En total se realizaron cuatro (4) talleres, cada uno con un promedio de 4 participantes y 4 entrevistas en profundidad.

Para la finalidad de este artículo se analizaron los segmentos de los resultados relacionados con los sentidos y significados sobre lo político y su relación con el delito. La reflexión se apoyó adicionalmente en la revisión teórico-conceptual realizada en el marco de la investigación institucional La Justicia Restaurativa en el Sistema de Responsabilidad Penal para Adolescentes y la dimensión ética en los Jóvenes y la Comunidad (2015 -2016).

\section{Una mirada analítica a los resultados El delito y el sentido de la identidad individual y colectiva}

"Yo sí prefiero ser un diablito a no ser 'nadie""

(Adolescente de 15 años, bajo medida no privativa de libertad por hurto).

El análisis de los talleres y entrevistas a los jóvenes muestra que la vinculación a actividades delictivas se va configurando para los jóvenes como sentidos de vida colectivos, a consecuencia de no hallarle sentido a su vida diaria. Para los jóvenes participantes, el proceso de construcción de identidad es asociado con la tenencia de poder, categoría que a su vez se asocia con la tenencia de dinero.

En la vida cotidiana se nombran como 'nadie' considerándose, de alguna manera, como excluidos de escenarios sociales que constituyan algún valor para ellos. La escuela, por ejemplo, no supone un escenario de inclusión social, ni tampoco un medio que les permita incluirse socialmente, pues la identidad y la inclusión social, desde su mirada, está absolutamente ligada al dinero; y la escuela, en la significación que han hecho de esta, no constituye una ruta para conseguirlo.

"...Al principio tu estudias porque lo que quieres es salir adelante, ser alguien en la vida, tener platica pa ayudar a tu familia, pero entonces llegas a un punto en el colegio que, digamos, tu sientes que no te va bien, no entiendes nada, no te gusta, todavía te faltan un poco de años y además ni siquiera sabes si cuando salgas vas a conseguir un 
trabajo, porque tampoco es que haya camello, ${ }^{5}$ y entonces ya optas por otras cosas. Yo empecé primero por trabajar, pero entonces no ganaba mucho y si me remataba y entonces ya viene el querer tener más plata [...] todo es la plata porque la plata es el poder en el barrio, tú ya eres más respetado bien montados, con tenis bien montado, eso es como normal" (Adolescente de 17 años, hombre, bajo medida privativa de libertad por Hurto Calificado).

Así, una de las búsquedas centrales que los jóvenes expresan, y que se relaciona con el proceso para vincularse a conductas delictivas, es la búsqueda de una identidad social.

"Antes de meterme con la gente dura del barrio, no era nadie, [...] si me entiende ahora me veo, me respetan, porque ya la gente ya va sabiendo quien soy yo, que tengo poder en el barrio, incluso cada vez que me pilla la policía eso es un video en el barrio eso todo el mundo habla de mí y algunos me apoyan porque es que también uno ha dado plata, en el barrio conviene que se mueva la plata, entonces como que se queja pero también se apoya" (Adolescente de 17 años, hombre, bajo medida privativa de libertad por hurto calificado y agravado).

Uno de los elementos que atraviesa todos los discursos de los jóvenes participantes en el estudio estuvo referido a 'ser alguien'. El significado de 'ser alguien' es para los jóvenes tener un lugar en la sociedad que los haga visibles; a su vez, ese lugar parece estar vinculado en esas redes de significado al dinero, así, el dinero se configura para ellos y ellas como una herramienta de poder, identidad y justicia. No obstante, esta significación que hacen los jóvenes de identidad, de justicia y del dinero mismo, puede resultar bastante coherente si se analiza a la luz de la pregunta ¿Quiénes son los jóvenes que están bajo medida privativa de libertad?

Las prácticas adolescentes, y las adolescencias que se configuran en las sociedades, son reflejo de dinámicas y características socioeconómicas, políticas y culturales, y la configuración de la adolescencia vinculada al delito no es una excepción. Según Krauskopf (2000), el desarrollo juvenil es resultado de una delicada interacción con los entes sociales del entorno, que tiene como referente no solo una biografía individual, sino también la historia y el presente de su sociedad.

Según datos aportados por UNICEF en el IV foro del Observatorio del Sistema de responsabilidad penal Adolescente (Mayo de 2013) el 95 \% de los jóvenes privados de libertad son pobres. El informe mundial de la infancia, realizado por esta misma organización, (Citado por Carrera, 2012) señala que: "Los adolescentes que corren un mayor riesgo en entrar en conflicto con la ley son a menudo el producto de difíciles

\footnotetext{
${ }^{5}$ Palabra usada por algunos grupos de jóvenes para referirse a trabajo o puestos de trabajo.
} 
circunstancias familiares que podrían incluir la pobreza, la ruptura familiar, el abuso de los progenitores o el alcoholismo" (UNICEF, 2011, p. 55).

Si bien ser pobre no necesariamente constituye ser invisible, sin duda sí lo es para un adolescente en un país donde el dinero ocupa uno de los valores centrales en la sociedad. La mayoría de los adolescentes vinculados al SRPA deben entonces no solo atravesar por las crisis propias que supone esta etapa del ciclo vital (la adolescencia), sino además enfrentarse a los obstáculos y riesgos asociados a la pobreza, la inequidad y la vulnerabilidad social, combinación que al final parece resolverse en la equiparación de dos preguntas: ¿Quién soy? y ¿Qué tengo? y para ellos y ellas parece cobrar más sentido la respuesta "soy un delincuente" a "no soy nadie".

"Eso del parche ${ }^{6}$ no es solo en las vueltas, entre nosotros, por ejemplo, somos legales, leales, y yo se que más de uno sabe que con quien cuenta, y es que uno comparte con el parche cosas que son de ponerse en la vida y la muerte, también es con las drogas ..." (Adolescente, mujer, 17 años, bajo medida de privación de libertad por hurto calificado).

\footnotetext{
${ }^{6}$ Palabra usada por algunos grupos de jóvenes para referirse al grupo al que pertenecen, frecuentemente asociado a vinculaciones de ocio, algunos movimientos culturales barriales y en este caso específicamente vinculado a acciones delictivas.
} 


\section{Territorialidad, ética y delincuencia juvenil}

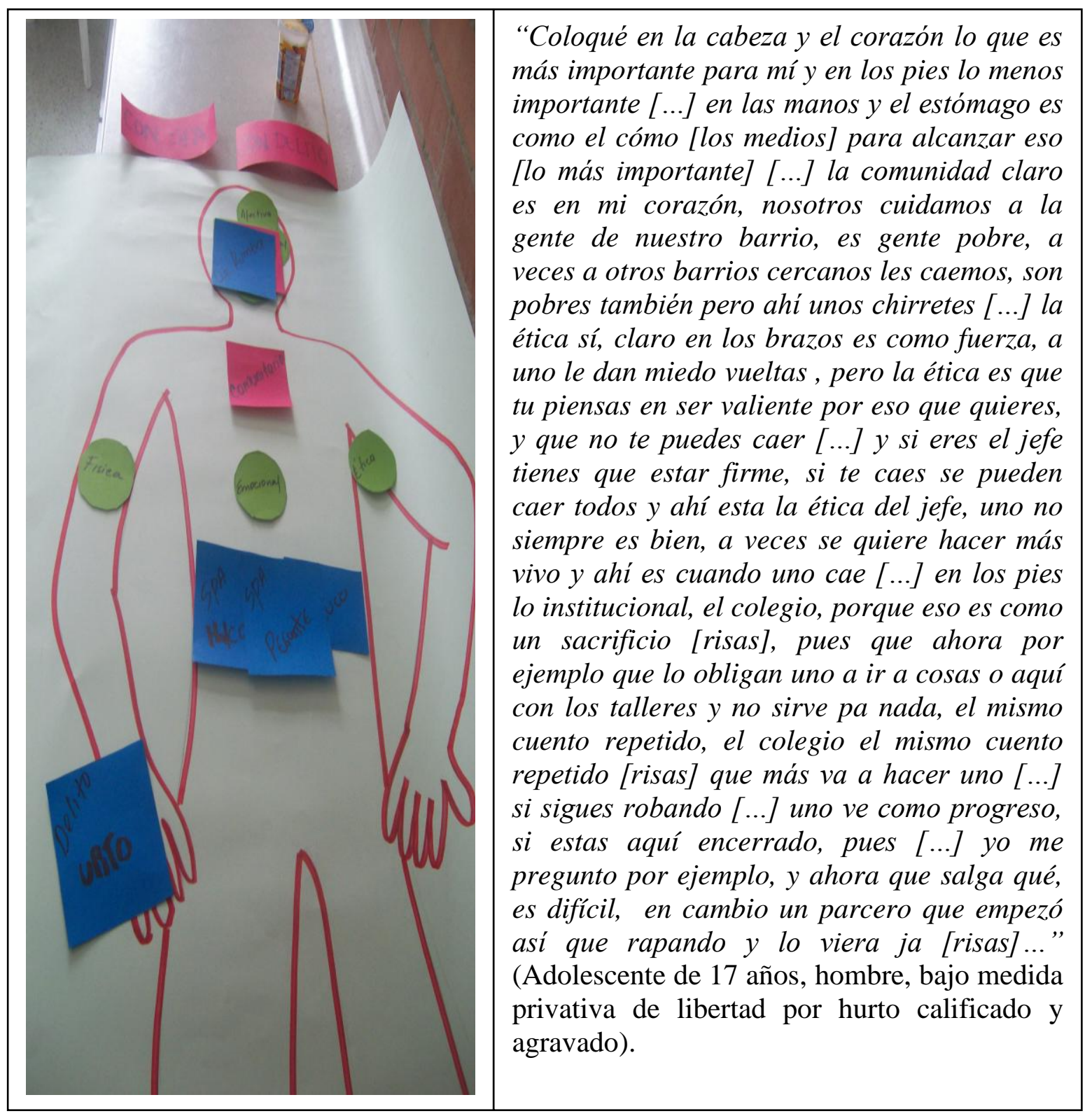

Tomado de: Cienfuegos, A. (Octubre, 2013) Sentidos y significados sobre las drogas y el delito en jóvenes vinculados al Sistema de Responsabilidad Penal Adolescente en Bogotá. Anexo G -Tesis de Maestría. Universidad Javeriana - Bogotá, Colombia.

Para Reguillo (2003) el sentido está siempre siendo, armándose en un continuum simbólico que desvanece fronteras, márgenes y límites. Para los jóvenes vinculados al delito, la legalidad, lo legal, no supone los límites relacionados con lo ético, por el contrario, los límites parecen, desde su mirada, estar producidos por una incomprensión de la vida en el territorio atravesada por la exclusión. Asimismo, la ética 
se configura como un asunto de valentía que tiene que ver con la lealtad con la grupalidad y la firmeza para alcanzar propósitos, muchas veces asociados a actos delictivos.

En sus relatos se encuentra lo ético como una dimensión ante la cual no hay conflictividad porque sus "actos valientes" (Mujer, 15 años, bajo medida privativa de libertad por tentativa de homicidio) están cargados de razones relacionadas con la satisfacción de necesidades básicas insatisfechas, pero también asociadas a matices de lo político; como defender el territorio, visibilizar el papel de ellos y los suyos en la sociedad, la consolidación del poder frente a los otros, la identificación y ocupación de un rol que les dote de identidad en medio de la invisibilidad percibida, es decir, una búsqueda de lo justo que coloca esa responsabilidad subjetiva del adolescente como compartida con el Estado.

Para Carrera (2012) la noción de responsabilidad subjetiva en el caso de adolescentes vinculados al delito, es solo una de las caras de la moneda en la que la otra parte es la vulnerabilidad social. Esto resulta fundamental para comprender que el fenómeno de la delincuencia juvenil es una problemática social que no puede resolverse solo con leyes penales y que requiere de una perspectiva holística que disminuya los prejuicios sobre los adolescentes y reconozca sus matices políticos en relación con las luchas implícitas de muchos adolescentes que se vinculan al delito y a bandas juveniles en torno a este.

\section{Lo político desde la mirada de adolescentes en conflicto con la ley}

En la mayoría de relatos predomina un desencanto por lo institucional, lo cual identifican con lo político, y ambas categorías aparecen dotadas de características negativas. Lo político es asociado a corrupción, injusticia, inequidad y riqueza; no obstante, se observa en algunos relatos afinidades por lo político, desde una perspectiva más asociada a legitimar ciertos valores que asocian con la política y que relatan como compartidos con ellos como grupo.

"...les importa es la plata, a nosotros también, están es buscando la oportunidad pa robar, igual por acá, pero esta es en chiquito, allá si son vueltas de miles de miles, [referido a los políticos]..." (Adolescente, mujer de 17 años, bajo medida privativa de libertad por tentativa de homicidio).

"...Pues en el barrio eso no funciona, hay gente que de las juntas locales y que quieren mejorar el barrio, pero eso sin plata, eso no es política" (Adolescente de 17 años, hombre, bajo medida privativa de libertad por hurto calificado y agravado).

De otra parte, categorías como participación o ciudadanía no son asociadas a lo político y son leídas como categorías asociadas a lo institucional que no tienen ningún 
beneficio o sentido para los jóvenes. "Carreta" ciudadanía activa en los adolescentes aparece como un elemento propio de la concepción del adolescente dentro del SRPA, como sujetos de derechos y sujetos de responsabilidades.

\section{Las políticas de prevención de la delincuencia juvenil desde la mirada de los adolescentes en conflicto con la ley}

Dentro de los relatos asociados a preguntas tales como: ¿Cómo podría prevenirse la delincuencia juvenil?, ¿Qué estrategias creen que pueden ser útiles?, ¿Qué recomendaciones haría a las políticas de prevención de la delincuencia en los jóvenes? la educación es ubicada, paradójicamente, en un lugar central, y digo paradójicamente porque es uno de los escenarios cotidianos que se identificó con menor valor para los jóvenes; no obstante, los jóvenes reconocen que la reconfiguración de la escuela podría ser central en buscar soluciones a este fenómeno.

"...Primero que todo el querer tener dinero, el querer progresar y el querer tener las cosas fáciles no se puede evitar porque así es este país, plata [...] Yo pienso que debe empezarse por el colegio, en él deberían brindar las herramientas para que uno pueda ir progresando y usted sea menos influenciado, más oportunidades de trabajo, más oportunidades productivas, menos tiempo en el salón, y mirar también la economía de la familia, todo eso aunque no solo lo productivo, porque una persona con plata compra cualquier vaina, hace lo que sea y de la plata salen también las drogas, como te explico, es en brindarle una ayuda mas allá a la familia y que uno sea menos influenciable y pueda usar bien el dinero [...] debería ser el colegio y trabajo a la vez desde que uno entra al bachillerato para que él cuando ya va a terminar sus estudios, salga por lo menos con una base, para poderse parar y algunas proyecciones de vida, no como capacitación manual y eso, sino trabajos de verdad en algunas empresas como puede ser en horario contrario, puede ser de seis de la mañana a doce del día estudiando y de doce a cinco trabajando, y te paguen algo bueno, entonces el pelao se mantendría ocupado, ganaría plata, tendría pares menos nocivos, y sentiría que está progresando [...] yo pienso que digamos las malas amistades, el querer tener plata, el querer progresar y ser alguien, en muchos aspectos, es lo que hace perder el colegio, y cuando ya uno se sale o lo coge de vueltas ya se jodió [risas] pues ya es más difícil quiero decir" (Adolescente de 17 años, hombre, bajo medida privativa de libertad por hurto calificado y agravado).

\footnotetext{
${ }^{7}$ Palabra usada por algunos grupos de jóvenes para referirse a discursos, palabras u otra comunicación verbal que no tiene sentido, es irreal, falsa o difícilmente puede ser coherente con la realidad o las acciones de la persona que la predica.
} 
Desde el discurso de los jóvenes la reconfiguración que necesita la educación es una configuración hacia "una escuela productiva" situando al dinero nuevamente como elemento central en el desarrollo y la posibilidad de prevenir la delincuencia juvenil. Vale la pena detenerse en los elementos que llevan a esta concepción de la solución por parte de ellos y ellas.

El dilema entre el presente y el futuro constituye quizá la columna vertebral de los significados ambivalentes que tienen los jóvenes frente a la educación. El escenario escolar para los adolescentes es como "un sueño prometido, nunca cumplido" (Adolescente, mujer, 15 años, bajo medida privativa de libertad por tentativa de homicidio) la escuela resulta el medio para "progresar y ser alguien en la vida" lo cual, por supuesto, es un sentido reproducido socialmente. La relación entre el acceso a la educación secundaria y las posibilidades futuras de las personas en el mercado laboral (Gaviria \& Barrientos, 2001) es contemplada y expresada abiertamente en documentos gubernamentales, académicos, medios de comunicación, etc. Pero, ¿serán las únicas relaciones que debe establecer el adolescente con el colegio?, es posible para los adolescentes permanecer allí y sentir satisfacción por algo que solo les significa futuro?

Para las y los adolescentes participantes en este estudio esto parece realmente difícil. El escenario escolar es narrado por ellos y ellas como "un deber", "un sacrificio" un escenario para "salir adelante" "progresar" "ser alguien en la vida" "proyectarse en el futuro"; el problema es que en el presente no significa nada más que un escenario "sin sentido"

El colegio o se convierte en un "lugar de paso" en el que parcialmente se está, pero al que no sienten que pertenecen, o se buscan "emociones" y "adrenalina" dentro de él convirtiéndolo en un escenario para el consumo, la venta de SPA, la violencia y las conquistas amorosas, o se deserta de él.

"[...] pues yo casi siempre capo clase pero a veces voy y parcho con los de allá, aunque ellos son más sanos, pero también allá tengo una nenita que me acompaña en vueltas y que la quiero, pero ( $\mathrm{mmmm}$ ) que más me gusta...? [silencio] difícil [risas]" (Adolescente, hombre, 15 años, bajo medida privativa de libertad por porte de sustancias ilegales).

"Yo casi no iba al colegio, además no entiendo nada, pero de todas maneras me tocaba ir y tal porque mi mamá era pendiente y salía a robar en uniforme y la gente entonces no piensa que uno la va a robar" (Adolescente, 15 años, sanción de reglas de conducta por hurto).

Para los jóvenes, el futuro prometido por el colegio no es suficiente ni "rentable"; este tiene sentido solo en la medida en que signifique "progresar" y el progreso está medido en dinero, poder y reconocimiento, los cuales a su vez son asociados con identidad. Así, la escuela se configura inicialmente como un medio para "surgir", alcanzar estos 
elementos de alto valor, pero poco a poco y en la medida en que la idea de progresodinero se fortalece en su vida y la idea de disfrute se desvanece en su presente dentro de este escenario, les resulta una mala ecuación el tiempo de espera del colegio para "progresar" en comparación con el tiempo de espera del delito para "ir progresando".

La investigación científica sobre los factores de riesgo del consumo de SPA permite saber que los adolescentes tienden a dar prioridad a la gratificación inmediata y a la eliminación parcial de aquello que les resulta aversivo (Varela \& Salazar, 2007). ¿Podríamos, bajo esta evidencia científica, pedirle a los jóvenes que se mantengan en un sistema únicamente por lo que esto significará en un futuro?, ¿cuáles son las gratificaciones inmediatas que obtiene el joven en el colegio, si para ellos y ellas está desprovisto de sentido en el presente?, ¿no es reproducida la idea de colegio-esfuerzorecompensa futura dentro de la comunidad educativa constantemente?, ¿debería ser el colegio únicamente un medio para generar capital humano o debería ser un espacio de desarrollo vital para los jóvenes?

Aprender, para los y las adolescentes, definitivamente no es un goce o placer, no es una actividad que tenga recompensas significativas e inmediatas; por el contrario, algunos lo narran como un escenario "frustrante", "el colegio es difícil y aunque la calle no es fácil, la plata y la diversión es inmediata" (Adolescente, hombre 15 años, bajo medida privativa de libertad por porte de sustancias ilegales).

\section{Una mirada a las políticas de prevención y atención de la delincuencia juvenil en Colombia}

Las políticas orientadas a atender el fenómeno de la delincuencia juvenil en Colombia parecen ser resultado de la comprensión y el reconocimiento evidente de la relación entre exclusión social, pobreza y delincuencia juvenil. Producto de esta comprensión, se encuentran leyes como la 1577 de 2012, "por medio de la cual se establecen estímulos tributarios y otros, con el fin de adoptar medidas especiales para la rehabilitación e inclusión social de jóvenes con alto grado de emergencia social, pandillismo y violencia juvenil" (Ley 1577 de 2012. p. 1).

Asimismo, parece comprenderse, en el marco de estas políticas, la responsabilidad compartida entre el Estado, los adolescentes y las familias en el fenómeno de la delincuencia juvenil. Como resultado de esto se promulga un Sistema de Responsabilidad Penal Adolescente que reconoce al adolescente como sujeto de derechos, frente al cual el Estado tiene la responsabilidad de garantizarlos y restablecerlos $y$, simultáneamente, como sujeto responsable penalmente, lo que supone un sistema de naturaleza sancionatoria y pedagógica que busca "restablecer sus derechos, brindarles opciones de inclusión social y favorecer su ejercicio ciudadano responsable, autónomo y respetuoso de la convivencia y las diversas expresiones de vida" (ICBF, 2013 p. 4). 
Adicionalmente, desde el horizonte de las políticas en el país, se parece haber comprendido la importancia de enfocarse en la prevención de la delincuencia juvenil en lugar del enfoque punitivo hacia los jóvenes, tanto es así que la ley 1453 de 2011, reglamentada a través del Decreto Nacional 079 de 2012, y por medio de la cual "se reforma el Código Penal, el Código de Procedimiento Penal, el Código de Infancia y Adolescencia, las reglas sobre extinción de dominio y se dictan otras disposiciones en materia de seguridad" determina en su artículo 95, que se tendrá un plazo no mayor a 6 meses para diseñar, desde un enfoque de derechos, la política de prevención de la delincuencia juvenil.

Los discursos contenidos en estas políticas parecen no distar en gran medida de elementos que se develan en los discursos de los jóvenes; sin embargo, el fenómeno de la delincuencia juvenil no muestra cambios significativos en los últimos años, y, por el contrario, parece venir en aumento. ¿Cuáles son entonces los obstáculos en relación con estas políticas orientadas a atender y prevenir la delincuencia juvenil? Los principios y concepciones que guían estas políticas en realidad no se cumplen; la concepción de delincuencia juvenil previamente citada y respaldada por cada una de estas normas es débilmente coherente con las realidades de la implementación de las políticas.

En general, frente a esta pregunta podrían identificarse muchos más aspectos de los que se pretenden anotar en este artículo; con todo, uno de ellos, en el que se pretende hacer especial énfasis, es la dimensión política que interviene en este fenómeno, desde la mirada de las y los jóvenes.

\section{Conclusiones}

Los relatos juveniles analizados en este artículo dejan ver que la problemática de la delincuencia juvenil no es solo un asunto técnico que debe resolverse desde la intervención punitiva y/o asistencial, es también, al parecer, un asunto político que implica la comprensión de la naturaleza de identidades colectivas en contextos de exclusión social, y el reconocimiento de los jóvenes vinculados al delito como actores con necesidades sociopolíticas desatendidas.

La búsqueda de identidad social, que se configura para los jóvenes como un sentido central en la vinculación a grupos con fines delictivos, supone una connotación política, considerando lo político como dimensión humana. En términos de Mouffe (2011), "como el espacio de poder, conflicto y antagonismo" (p. 16). Se observa en los relatos aportados por los jóvenes que uno de los elementos centrales en relación con la vinculación a actos delictivos y su continuidad en estos, es el sentido otorgado al poder, el cual se constituye en un motor de búsqueda de identidad no solamente asociada a la búsqueda de dinero para satisfacción de necesidades básicas, sino el poder a través del dinero como medio para la construcción de identidad individual y colectiva. 
En esta construcción de identidad individual y colectiva, el espacio de conflicto y la confrontación con el poder se sitúa entre el mismo conflicto con la ley y la disputa por el poder en el territorio.

Asimismo, la racionalidad comunicativa, identificada por Mouffe (2011) como uno de los paradigmas en la definición de lo político, supone la relación de esta dimensión con un campo deliberativo donde lo político es aprendido mediante la ética o la moralidad. En los significados asociados a 'lo ético' que expresan los jóvenes, se evidencia una correspondencia entre el sentido otorgado al poder como medio para la construcción de identidad y la ética más allá de los límites de la legalidad, como un asunto de valentía que tiene que ver con la lealtad, con la grupalidad y la firmeza para alcanzar propósitos individuales y colectivos, muchas veces asociados a actos delictivos. Tanto el poder como la ética constituyen aspectos muy ligados a mantener y proteger una identidad colectiva.

Así, lo ético en estos jóvenes, considerado por Montero (2001) como "la reflexión general de carácter social, relacional, de la cual se derivan los mandamientos específicos que cada persona deberá implementar en su conducta cotidiana" (p. 5) no es un objeto a ser transformado desde discursos externos, pues forma parte de un entramado de sentidos y significados que se construyen en un territorio donde la noción de justicia, poder y ética atraviesa por la dimensión política de los jóvenes y los grupos como uno de los aspectos articulados al sentido que tiene la delincuencia para muchos jóvenes en Bogotá.

Ahora bien, ¿inciden las políticas de prevención y atención de la delincuencia en este aspecto? Los lineamientos de políticas públicas para la prevención y atención de la delincuencia juvenil destacan como uno de los propósitos centrales de su quehacer el "favorecer al ejercicio ciudadano de los jóvenes que se vinculan a delitos" (ICBF, 2013, p. 4); no obstante, la estigmatización social hacia estos adolescentes es cada vez mayor en los medios de comunicación, la comunidad en general y desde el propio Estado.

Las políticas públicas para hacer frente al fenómeno parecen suponer que las leyes en sí mismas transforman imaginarios sociales y que, por tanto, la desestigmatización y despatologización de los adolescentes vinculados al delito no es asunto de estas. No hay pedagogía de las leyes y políticas de prevención de la delincuencia juvenil, además, las políticas para afrontar el fenómeno escasamente contemplan estrategias pedagógicas y mediáticas orientadas a la desestigmatización social de los adolescentes que se vinculan al delito; en su lugar, parecen haber olas intermitentes de estigmatización y sensacionalismo en torno a la delincuencia juvenil desde los medios de comunicación y diversos sectores políticos y sociales. ¿Cómo pretenden entonces las políticas aportar al desarrollo de identidades sociales y colectivas positivas de los jóvenes?, ¿es posible generar transformaciones éticas desde discursos y valores externos? 
La desestigmatización social y la despatologización de los jóvenes en riesgo de vincularse al delito y de quienes ya lo han hecho son procesos centrales, que desde las políticas públicas podrían aportar a la dimensión ético-política de los jóvenes y los grupos juveniles; sin embargo, no son procesos en los que realmente dichas políticas trabajen.

Adicionalmente, la dificultad de incidir en la dimensión ético-política de los jóvenes y los grupos juveniles vinculados al delito también responde a una debilidad de implementación y financiación del actual SRPA, el cual coloca los principios orientadores del sistema, (que supondrían por lo menos una intervención convencional en la dimensión ética), como ideales en el papel y no como escenarios fácticos de posibilidades para la transformación, educación y resocialización de los jóvenes.

En 2011, el informe de la Comisión Evaluadora del Sistema de Responsabilidad Penal Adolescente en Colombia ${ }^{8}$ estableció algunos puntos críticos del sistema, en su mayoría relacionados con aspectos de implementación, tales como: "Ausencia de ente rector del sistema, ausencia de recursos financieros y técnicos, ausencia de espacios físicos adecuados, necesidades de capacitación del talento humano que interviene en todas las etapas del proceso sancionatorio, ausencia de programas para la salud mental y de atención del consumo de sustancias psicoactivas"; y hoy, tres años después en el marco del IV foro del sistema de responsabilidad penal adolescente (Observatorio del Sistema De Responsabilidad Penal Adolescente OSRPA, Mayo, 2015) se identifican las mismas falencias y algunas otras prácticas incoherentes en relación con el marco ético y político de las políticas de atención del fenómeno de la delincuencia juvenil en Colombia. Asimismo, en torno a la prevención, no se cuenta hoy, tres años después, con la política de prevención de la delincuencia juvenil ordenada por la ley 1453 de 2011, antes citada.

Estas condiciones actuales resultan obstáculos transversales para un sistema que pretenda comprender e incidir en la naturaleza de identidades colectivas, en las necesidades sociopolíticas de estos jóvenes y que busque transformaciones éticas y resignificaciones en lo político. Difícilmente un sistema en estas condiciones actuales pueda generar procesos integrales que incluyan y sean acordes con la desestigmatización y despatologización social de estos 'jóvenes delincuentes'.

En conclusión, no solo se espera aportar con este análisis a la comprensión de la delincuencia juvenil desde las voces de los jóvenes inmersos en esta, sino también

\footnotetext{
${ }^{8}$ Instancia creada a través del artículo 110 de la Ley 1453 de 2011. Integrada por un (1) delegado/a del Ministerio del Interior, un (1) delegado/a del ICBF, un (1) delegado/a de la Procuraduría, un (1) delegado/a de la Defensoría del Pueblo, un (1) delegado/a de la Fiscalía, un (1) delegado/a del Consejo Superior de la Judicatura, un (1) delegado/a de la Policía de Infancia y Adolescencia, un (1) delegado/a de la Alianza por la Niñez, un (1) delegados/as del Observatorio del Sistema de Responsabilidad Penal para Adolescentes de la Universidad Nacional, dos (2) delegados/as de entidades territoriales. La Comisión tiene como propósito verificar que el Sistema cumpla la finalidad pedagógica, específica y diferenciada y que garantice la justicia restaurativa, la verdad y la reparación del daño, para lo cual fue creado.
} 
hacer un llamado a los tomadores de decisiones de políticas públicas, frente al reconocimiento de la complejidad del fenómeno y por tanto la incompatibilidad con un modelo simplificado de implementación. Actualmente, las políticas para afrontar la delincuencia juvenil en Colombia parecen tener un amplio desarrollo en la construcción de principios y lineamientos propios de las sociedades democráticas en los documentos de política, pero una ausencia de voluntad política en la praxis, no solo para la financiación adecuada del sistema, sino también para reconocer predominantemente a estos jóvenes como sujetos de derechos más que como delincuentes.

La visión del 'delincuente' reforzada en imaginarios colectivos de rechazo y el punitivismo en la sociedad deja a los adolescentes en un limbo entre adolescentes vulnerables y adolescentes responsables que en la práctica parecen no ser más que un delincuente adulto común. Esta realidad reproduce en los jóvenes los sentidos y significados asociados a la dimensión ético-política que refuerzan, reproducen y mantienen el delito.

\section{Referencias}

Carrera, C. (2012). Entre la vulnerabilidad social y la responsabilidad subjetiva: una mirada a los adolescentes en conflicto con la ley en Soacha. Revista Eleuthera. 8, $142-155$.

Cienfuegos, A. (2013). Sentidos y Significados sobre las drogas y el delito en Jóvenes vinculados al Sistema de Responsabilidad Penal adolescente. (Tesis de maestría inédita). Facultad de Ciencias Políticas. Universidad Javeriana.

Gaviria, A., y Barrientos, J. (2001). Determinantes de la calidad de la educación en Colombia. Archivos de Economía, Publicación provisional. 1-76.

Ibáñez, J. (1994). El regreso del sujeto: la investigación social de segundo orden. Madrid: Siglo XXI.

ICBF - Instituto Colombiano de Bienestar Familiar (2013). Los Adolescentes en el Sistema de Responsabilidad Penal para Adolescentes. Colombia: Autor.

Krauskopf, D. (2000). Dimensiones críticas en la participación social de las juventudes. La participación social y política de los jóvenes en el horizonte del nuevo siglo, 119-134.

Ley 1577. Congreso de la República. Colombia, 20 de septiembre de 2012.

Ley 1453. Congreso de la República. Colombia, 24 de Junio de 2011.

Mouffe, C. (2011). En torno a lo político. Buenos Aires: Fondo de Cultura Económica.

Montero, M. (2001). Ética y Política en Psicología: Las dimensiones no reconocidas. Athenea Digital. Revista de Pensamiento e Investigación Social. Abril, 1-10.

Odoñez-Matamoros, G. (2013). Manual de Análisis y diseño de políticas públicas. Bogotá. Universidad Externado de Colombia. 
De Prácticas y discursos/ Universidad Nacional del Nordeste/ Centro de Estudios Sociales

Observatorio del Sistema De Responsabilidad Penal Adolescente OSRPA, (Mayo, 2015). Reforma al Sistema de responsabilidad penal adolescente. Realidades, retos y oportunidades. IV foro de Responsabilidad penal adolescente. Universidad Nacional de Colombia.

Reguillo, R. (2003). Las culturas juveniles: un campo de estudio; breve agenda para la discusión. Revista Brasileira de Educação. 23, 103-118. 